\section{Thoracic epidural clonidine and morphine for postoperative pain relief}

Yukinobu Anzai MD, ${ }^{*}$ Toshiaki Nishikawa MD $\dagger$
This study was undertaken to evaluate the potentiation of the postoperative analgesic effect of thoracic epidural morphine by coadministration of thoracic epidural clonidine in a randomized double-blinded design. Twenty patients underwent radical gastrectomy under combined general anaesthesia (enflurane and nitrous oxide/oxygen) and epidural anaesthesia with local anaesthetics. They received a thoracic epidural bolus injection of either $0.05 \mathrm{mg} \cdot \mathrm{kg}^{-1}$ morphine plus $3 \mu \mathrm{g} \cdot \mathrm{kg}^{-1}$ clonidine $(M+C$ group; $n=10)$ or $0.05 \mathrm{mg} \cdot \mathrm{kg}^{-1}$ morphine alone. (M group; $n=10$ ) immediately before completion of surgery. All patients received iv morphine via patient-controlled analgesia (PCA) equipment for $24 \mathrm{hr}$ postoperative period, and the PCA iv consumption of morphine was the primary variable of efficacy of the analgesic regimen. In addition, data analyses included mean arterial blood pressure, heart rate, respiratory rate, arterial blood gas measurement, sedation score, and visual analogue pain scale score (VAS). The cumulative number of iv morphine injections via PCA was less in the $M+C$ group than in the $M$ group at each hour for $24 \mathrm{hr}$ postoperative period $(P<0.05)$, while the numbers of $P C A$ morphine injections per hour beyond nine hours after surgery were higher in the

\section{Key words}

ANALGESIA: postoperative, patient-controlled analgesia

(PCA), thoracic epidural;

ANALGESICS: clonidine, morphine;

PAIN: postoperative.

From the Department of Anaesthesia, Obihiro Kousei General Hospital,* and the Department of Anaesthesiology, University of Tsukuba. $\dagger$

This work was performed at the Department of Anaesthesia, Obihiro Kousei General Hospital, Obihiro City, Hokkaido, Japan.

Presented at the 2nd America-Japan Anesthesia Congress,

Honolulu, Hawaii, January, 1992.

*Presently, Department of Anaesthesia, Sapporo Maruyama Orthopedic Hospital.

Address correspondence to: Dr. Toshiaki Nishikawa,

Department of Anaesthesiology, Institute of Clinical Medicine,

University of Tsukuba, Tsukuba City, Ibaraki 305, Japan.

Accepted for publication 27th November, 1994.
$M$ group than in the $M+C$ group $(P<0.05)$. Sedation score was higher, and VAS and mean blood pressure were lower in the $M+C$ group only at one hour after surgery compared with the $M$ group. We conclude that the combined single thoracic epidural administration of morphine plus clonidine produces a more potent and longer lasting analgesia than does morphine alone.

Cette étude randomisée et à double insu a pour objectif de comparer l'effet potentialisateur de l'association morphineclonidine par épidurale thoracique à la morphine seule administrée par la même voie. Chez 20 patients soumis à une gastrectomie radicale, on combine une anesthésie générale (enflurane et protoxyde d'azote/oxygène) à une épidurale aux anesthésiques locaux. Immédiatement avant la fin de la chirurgie, ils reçoivent un bolus épidural thoracique soit de morphine $0,05 \mathrm{mg} \cdot \mathrm{kg}^{-1}$ plus clonidine $3 \mu \mathrm{g} \cdot \mathrm{kg}^{-1}$ (groupe $\mathrm{M}+\mathrm{C} ; \boldsymbol{n}=$ 10), soit de morphine $0,05 \mathrm{mg} \cdot \mathrm{kg}^{-1}$ (groupe $M ; n=10$ ). Pour vingt-quatre $h$ à la période postopératoire, tous les patients reçoivent de la morphine ì autocontrôlée (PCA), la consommation de morphine étant le principal critère d'évaluation de l'efficacité de la méthode d'analgésie. La pression artérielle moyenne, la fréquence cardiaque et respiratoire, l'analyse des gaz artériels, le score de sédation et l'échelle visuelle analogue (EVA) complètent l'analyse des données. Le nombre cumulatif des injections de morphine iv par PCA est moindre dans le groupe $M+C$ que dans le groupe $M$ à toutes les heures du postopératoire pour la période de $24 \mathrm{hr}(P<0,05)$; la fréquence; horaire des injections de morphine iv par PCA après les premières neuf heures postchirurgicales est plus élevée dans le groupe $M$ que dans le groupe $M+C(P<0,05)$. Le score de sédation est plus élevé, et l'EVA et la pression artérielle moyenne ne sont plus basses dans le groupe $M+C$ qu'à la première heure postchirurgicale comparativement au groupe $M$. Nous concluons que l'administration d'une seule dose de morphine associée à la clonidine produit une anesthésie plus puissante et de plus longue durée que la morphine seule.

Epidural clonidine, a partial alpha ${ }_{2}$ agonist, produces an antinociceptive effect ${ }^{1-4}$ or potentiates the analgesic effect of epidurally administered morphine. ${ }^{5}$ In animal models 
some data support a synergistic interaction between alpha $a_{2}$ adrenergic agonists and opioids at the spinal cord level. ${ }^{6,7}$ Because clonidine has no side effects common to opioids, ${ }^{8}$ it may prove to be an effective adjunct to epidural morphine for postoperative analgesia.

We compared the postoperative analgesic effect of a thoracic epidural bolus injection of morphine when administered with or without clonidine. In addition to the assessment of pain intensity using a visual analogue scale, we used patient-controlled analgesia (PCA) equipment, because PCA $\dot{i v}$ morphine requirements enable us to perform sensitive and objective assessment of postoperative pain and the analgesic effects of epidural morphine alone or epidural morphine plus clonidine. ${ }^{9}$

\section{Methods \\ Twenty ASA physical status 1 or 2 patients with gastric carcinoma scheduled for radical gastrectomy with lym- phadenectomy under general anaesthesia (enflurane and nitrous oxide/oxygen) plus thoracic epidural analgesia with local anaesthetics, were selected for study. The pro- tocol was approved by our Institutional Human Studies Committee. Informed consent was obtained from each patient. Patients were free of any neurological or car- diopulmonary disorder. All patients were instructed preoperatively in the use of a programmable PCA ma- chine (Harvard PCA, Bard, NJ). Preanaesthetic med- ication consisted of hydroxyzine $100 \mathrm{mg}$ and atropine sulfate $0.5 \mathrm{mg}$ im $60 \mathrm{~min}$ before arrival in the operating room.}

After patients were placed in the lateral decubitus position, an $18 \mathrm{G}$ epidural catheter was inserted through a Tuohy needle at the $\mathrm{T}_{6-7}$ or $\mathrm{T}_{7-8}$ intervertebral space. Following a test dose (1.5\% lidocaine $3 \mathrm{ml}$ with $1: 200,000$ epinephrine), the remaining 5-10 $\mathrm{ml}$ of the same solution was administered into the epidural space. Twenty minutes later, segmental analgesia was confirmed by pin-prick. Anaesthesia was induced with thiamylal $4-5 \mathrm{mg} \cdot \mathrm{kg}^{-1}$ and maintained with enflurane $0.6-1.0 \%$ inspired, and $67 \%$ nitrous oxide in oxygen. Tracheal intubation was facilitated by succinylcholine chloride $1 \mathrm{mg} \cdot \mathrm{kg}^{-1} i \mathrm{v}$. Immediately before completion of surgery, patients received a thoracic epidural bolus injection of either morphine 0.05 $\mathrm{mg} \cdot \mathrm{kg}^{-1}$ plus clonidine $3 \mu \mathrm{g} \cdot \mathrm{kg}^{-1}(\mathrm{M}+\mathrm{C}$ group, $n=$ 10) or $0.05 \mathrm{mg} \cdot \mathrm{kg}^{-1}$ morphine alone (M group, $n=$ 10 ), which were prepared in a total volume of $10 \mathrm{ml}$ by diluting with $0.9 \%$ saline.

After full recovery from general anaesthesia, all patients were transferred to the intensive care unit. Each patient received morphine $0.02 \mathrm{mg} \cdot \mathrm{kg}^{-1} i v$ via PCA with a three-minute lockout period as supplementary analgesia. The injection time of $i v$ morphine was recorded in the microcomputer of the PCA machine. Arterial
TABLE I Characteristics of patients

\begin{tabular}{lcl}
\hline & $\begin{array}{l}\text { Morphine plus clonidine } \\
(n=10)\end{array}$ & $\begin{array}{l}\text { Morphine alone } \\
(n=10)\end{array}$ \\
\hline Age (yr) & $53 \pm 3$ & $60 \pm 3$ \\
Weight (kg) & $54 \pm 3$ & $56 \pm 2$ \\
Height (cm) & $159 \pm 3$ & $162 \pm 1$ \\
Sex (M/F) & $5 / 5$ & $6 / 4$ \\
Surgical time (min) & $167 \pm 5$ & $154 \pm 6$ \\
\hline
\end{tabular}

Values are mean $\pm \mathrm{SE}$.

There were no differences between groups.

blood pressure, heart rate and respiratory rate were monitored by an automatic cuff, ECG, and impedance method, respectively. Arterial blood was analyzed for $\mathrm{pHa}, \mathrm{PaCO}_{2}, \mathrm{PaO}_{2}$ and base excess by Acid-Base Laboratory (model ABL 300, Radiometer, Copenhagen) at $1,3,6,9,12$, and $24 \mathrm{hr}$ after surgery. Mean blood pressure (MBP) was calculated as diastolic blood pressure plus $1 / 3 x$ pulse pressure. A six-point sedation score of 0 to $5(0=$ alert, tense, and inquisitive; $1=$ sedated, but not sleepy, with eyes opened; 2 = eyes closed almost continuously, responds immediately when spoken to; 3 $=$ eyes closed, responds to touch but not when spoken to; $4=$ wakes up only after repeated tactile or acoustic stimuli; $5=$ hard to wake up $)^{10}$ and a $10-\mathrm{cm}$ visual analogue scale of pain score (where 0 represented no pain and $10 \mathrm{~cm}$ represented "worst pain ever experienced") were checked by one of the staff in the intensive care unit who was blinded to the regimen of epidural analgesia. Ephedrine $5 \mathrm{mg}$ iv was administered when systolic blood pressure decreased to $<90 \mathrm{mmHg}$.

Values are given as mean \pm SE. Statistical analyses of the results were performed by analysis of variance with repeated measurements followed by Student's $t$ test with Bonferroni's correction. Comparisons between groups were performed using two-way analysis of variance followed by unpaired Student's $t$ test. Wilcoxon's signed rank test was used to compare the noncontinuous sedation scores between the two groups. Incidence of hypotensive episodes between groups was analyzed with chisquared test. $P$ values $<0.05$ were considered to be statistically significant.

\section{Results}

There were no differences in age, body weight, height, or sex ratio between the two groups of patients. These groups were similar in the duration of surgery (Table I). There was also no difference between groups in blood loss or fluid infused during and after surgery.

The cumulative number of morphine $i v$ injections via PCA was less in the $\mathrm{M}+\mathrm{C}$ group than in the $\mathrm{M}$ group at each hour for $24 \mathrm{hr}$ after surgery $(P<0.05$, Figure 


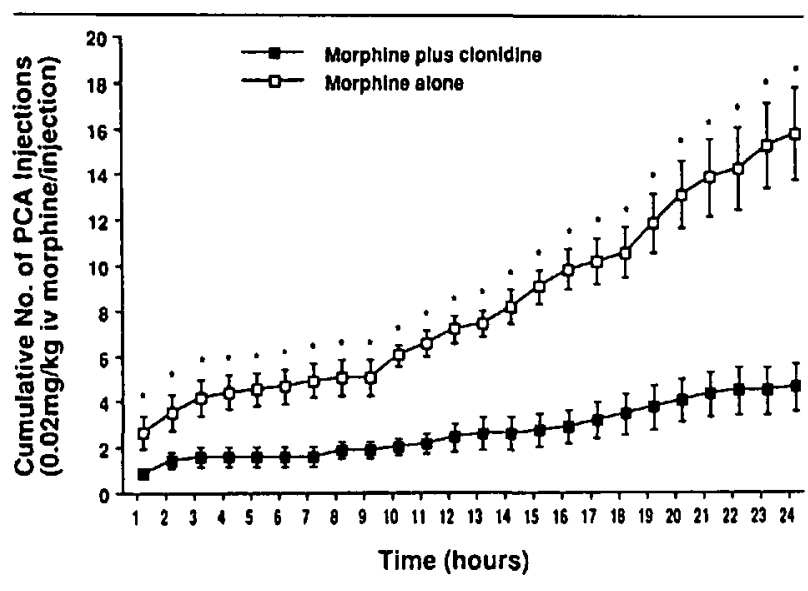

FIGURE 1 Cumulative number of intravenous injections of morphine $0.02 \mathrm{mg} \cdot \mathrm{kg}^{-1}$ via PCA in patients having received epidural morphine $(n=10)$ or morphine plus clonidine $(n=10)$ during $24 \mathrm{hr}$ after surgery. Mean $\pm S E$. There were differences between the two groups at each hour for $24 \mathrm{hr}\left({ }^{*} P<0.05\right)$.

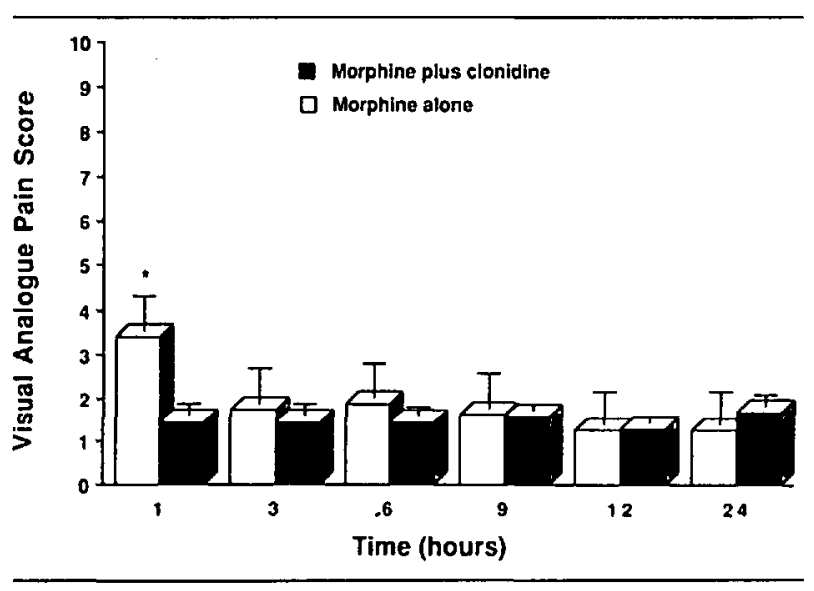

FIGURE 2 Changes in VAS in patients receiving epidural morphine $(n=10)$ or morphine plus clonidine $(n=10)$ at $1,3,6,9,12$, and 24 hr after surgery. Mean $\pm \mathrm{SE} .{ }^{*} P<0.05$ compared between the groups.

1), while the number of PCA morphine injections per hour beyond nine hours after surgery were higher in the $M$ group than in the $\mathrm{M}+\mathrm{C}$ group $(P<0.05$, Figure 1). Patients in the $M$ group showed a higher VAS score at one hour after surgery $(P<0.05)$ but, thereafter, a similar level of pain was demonstrated in both groups (Figure 2). The sedation scores in the $\mathrm{M}+\mathrm{C}$ group were higher than in the $\mathbf{M}$ group only at one hour after surgery $(P<0.05$, Figure 3). None of the patients was sedated to a degree that made them difficult to arouse.

Mean blood pressure was less in the $\mathrm{M}+\mathrm{C}$ group than in the $\mathrm{M}$ group only at one hour after surgery $(P<$ 0.05 , Figure 4). Hypotension (systolic blood pressure $<90$ $\mathrm{mmHg}$ ) was found during the $24 \mathrm{hr}$ postoperative period in five of ten patients receiving epidural morphine

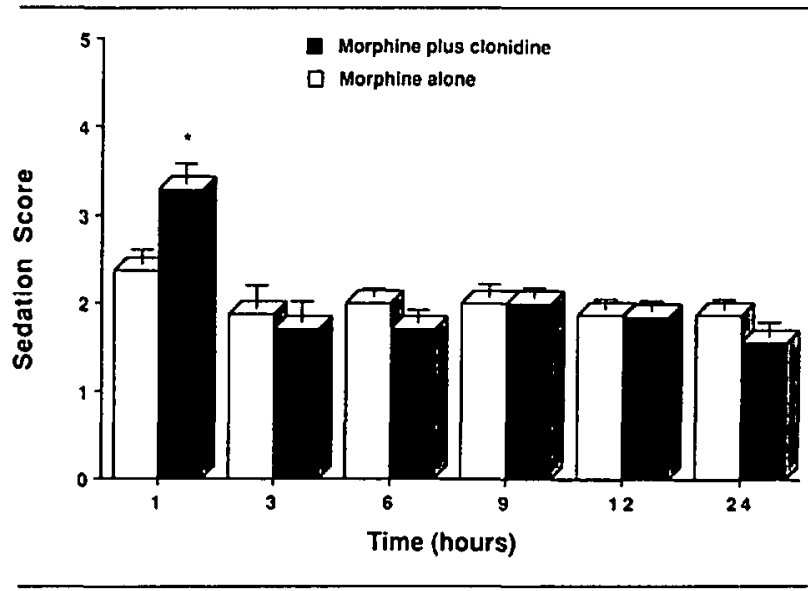

FIGURE 3 Changes in sedation score in patients receiving epidural morphine $(n=10)$ or morphine plus clonidine $(n=10)$ at $1,3,6,9$, 12 , and $24 \mathrm{hr}$ after surgery. Mean $\pm \mathrm{SE}$. $* P<0.05$ compared between the groups.

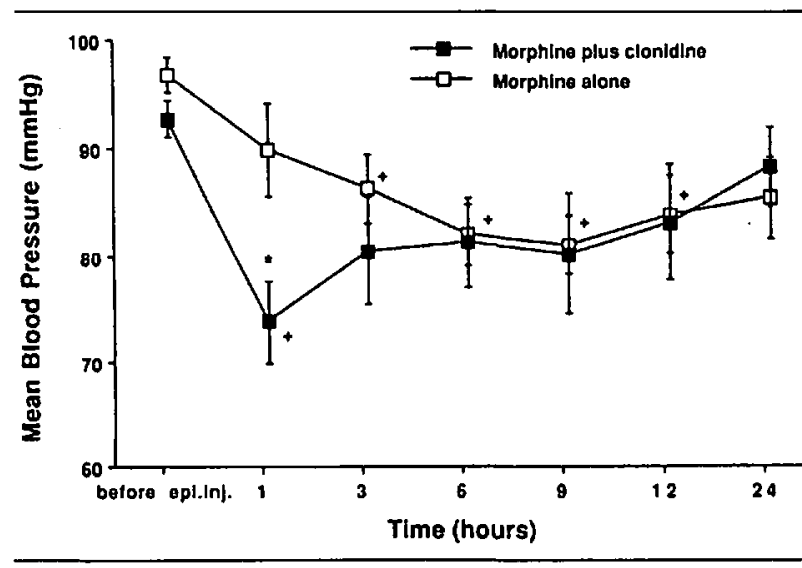

FIGURE 4 Changes in mean arterial pressure in patients receiving epidural morphine $(n=10)$ or morphine plus clonidine $(n=10)$ at 1 , $3,6,9,12$, and $24 \mathrm{hr}$ after surgery. Mean \pm SE. ${ }^{*} P<0.05$ compared between the groups. $+P<0.05$ compared with the value before epidural injection in each group.

plus clonidine. Although all these patients received ephedrine $5 \mathrm{mg} i v$, three patients needed colloid infusion of approximately $300 \mathrm{ml}$ to maintain blood pressure stable. However, no hypotensive episode was noted in any patient given epidural morphine alone $(P<0.05$, incidence of hypotension between groups). Heart rate was similar between groups throughout the study period (Table II), and no patient had heart rate $<50$ beats $\cdot \mathrm{min}^{-1}$ or required atropine. Respiratory rate was also comparable between groups (Table II).

Arterial blood gas values were similar between the two groups (Table III). The high values of postoperative $\mathrm{PaO}_{2}$ were due to breathing enriched oxygen via a face mask. There were no other adverse effects related to epidural clonidine in the postoperative period. 
TABLE II Heart rate and respiratory rate

\begin{tabular}{lll}
\hline & $\begin{array}{c}\text { Morphine plus clonidine } \\
(n=10)\end{array}$ & $\begin{array}{l}\text { Morphine alone } \\
(n=10)\end{array}$ \\
\hline Heart rate (beats' min $\left.^{-1}\right)$ & \\
I hr & $70 \pm 4$ & $77 \pm 5$ \\
$3 \mathrm{hr}$ & $75 \pm 2$ & $85 \pm 6$ \\
$6 \mathrm{hr}$ & $79 \pm 1$ & $77 \pm 5$ \\
$9 \mathrm{hr}$ & $76 \pm 2$ & $75 \pm 3$ \\
$12 \mathrm{hr}$ & $73 \pm 3$ & $73 \pm 3$ \\
$24 \mathrm{hr}$ & $73 \pm 2$ & $77 \pm 3$ \\
& & \\
Respiratory rate & $\left(\right.$ breaths $\left.\min ^{-1}\right)$ & \\
$1 \mathrm{hr}$ & $16 \pm 1$ & $19 \pm 1$ \\
$3 \mathrm{hr}$ & $15 \pm 1$ & $17 \pm 1$ \\
$6 \mathrm{hr}$ & $15 \pm 1$ & $15 \pm 1$ \\
$9 \mathrm{hr}$ & $15 \pm 1$ & $17 \pm 1$ \\
$12 \mathrm{hr}$ & $16 \pm 1$ & $17 \pm 1$ \\
$24 \mathrm{hr}$ & $18 \pm 1$ & $17 \pm 1$ \\
\hline
\end{tabular}

Values are mean $\pm \mathrm{SE}$.

There were no differences between groups.

\section{Discussion}

The main purpose of this study was to assess the postoperative analgesic effect of thoracic epidural clonidine combined with epidural morphine using PCA $i v$ morphine requirements in patients undergoing upper abdominal surgery, since PCA iv analgesia requirements are a reasonable measure of analgesic effectiveness of epidurally administered drugs. The addition of approximately $150 \mu \mathrm{g}$ clonidine to a single thoracic epidural dose of morphine resulted in a reduction in supplementary morphine requirements compared with epidural administration of morphine alone. In contrast to the accelerated increase in morphine requirements after nine hours in patients receiving morphine alone, the addition of clonidine eliminated such a progressive increment (Figure 1). These findings demonstrate that the addition of clonidine not only potentiates but also prolongs the thoracic epidural morphine analgesia after upper abdominal surgery. Motsch et al. ${ }^{5}$ demonstrated an enhanced morphine analgesia by clonidine, although the epidural level of administration of analgesics in their study was different from that in our study, and the $i v$ method of administration was by continuous infusion of morphine $6 \mathrm{mg}$ and clonidine $450 \mu \mathrm{g}$ during the first $24 \mathrm{hr}$ after surgery. They suggested that continuous epidural infusion of clonidine and morphine provided better pain relief than epidural bolus injections.

Few studies have demonstrated simultaneous potentiation of both the intensity and the duration of analgesia following epidural coadministration of clonidine and morphine. Despite intensified pain relief with epidural clonidine and morphine, Petit et al. showed no change in
TABLE III Arterial blood gas values

\begin{tabular}{|c|c|c|}
\hline & $\begin{array}{l}\text { Morphine plus clonidine } \\
(n=10)\end{array}$ & $\begin{array}{l}\text { Morphine alone } \\
(n=10)\end{array}$ \\
\hline \multicolumn{3}{|l|}{$p H a$} \\
\hline $1 \mathrm{hr}$ & $7.35 \pm 0.01$ & $7.34 \pm 0.01$ \\
\hline $3 \mathrm{hr}$ & $7.36 \pm 0.01$ & $7.36 \pm 0.02$ \\
\hline $6 \mathrm{hr}$ & $7.38 \pm 0.01$ & $7.39 \pm 0.01$ \\
\hline $9 \mathrm{hr}$ & $7.41 \pm 0.01$ & $7.40 \pm 0.01$ \\
\hline $12 \mathrm{hr}$ & $7.41 \pm 0.01$ & $7.41 \pm 0.01$ \\
\hline $24 \mathrm{hr}$ & $7.43 \pm 0.01$ & $7.39 \pm 0.01$ \\
\hline \multicolumn{3}{|c|}{$\mathrm{PaCO}_{2}(\mathrm{mmHg})$} \\
\hline $1 \mathrm{hr}$ & $42 \pm 2$ & $41 \pm 2$ \\
\hline $3 \mathrm{hr}$ & $42 \pm 2$ & $43 \pm 2$ \\
\hline $6 \mathrm{hr}$ & $42 \pm 1$ & $41 \pm 1$ \\
\hline $9 \mathrm{hr}$ & $40 \pm 1$ & $40 \pm 1$ \\
\hline $12 \mathrm{hr}$ & $39 \pm 1$ & $40 \pm 1$ \\
\hline $24 \mathrm{hr}$ & $38 \pm 1$ & $42 \pm 2$ \\
\hline \multicolumn{3}{|c|}{$\mathrm{PaO}_{2}(\mathrm{mmHg})$} \\
\hline $1 \mathrm{hr}$ & $140 \pm 6$ & $132 \pm 9$ \\
\hline $3 \mathrm{hr}$ & $141 \pm 9$ & $130 \pm 7$ \\
\hline $6 \mathrm{hr}$ & $140 \pm 8$ & $128 \pm 9$ \\
\hline $9 \mathrm{hr}$ & $134 \pm 7$ & $136 \pm 11$ \\
\hline $12 \mathrm{hr}$ & $133 \pm 7$ & $141 \pm 9$ \\
\hline $24 \mathrm{hr}$ & $134 \pm 8$ & $132 \pm 10$ \\
\hline \multicolumn{3}{|c|}{ Base excess $\left(m E q \cdot L^{-1}\right)$} \\
\hline $1 \mathrm{hr}$ & $-2.6 \pm 0.6$ & $-3.8 \pm 0.5$ \\
\hline $3 \mathrm{hr}$ & $-1.8 \pm 0.8$ & $-1.6 \pm 0.3$ \\
\hline $6 \mathrm{hr}$ & $-0.9 \pm 0.6$ & $-0.4 \pm 0.4$ \\
\hline $9 \mathrm{hr}$ & $0.0 \pm 0.4$ & $-0.1 \pm 0.3$ \\
\hline $12 \mathrm{hr}$ & $0.5 \pm 0.3$ & $0.5 \pm 0.4$ \\
\hline $24 \mathrm{hr}$ & $1.0 \pm 0.6$ & $0.4 \pm 0.5$ \\
\hline
\end{tabular}

Values are mean $\pm \mathrm{SE}$.

There were no differences between groups.

the duration of analgesia. ${ }^{11}$ In the combined use of epidural fentanyl and clonidine the degree of pain relief was not different from that of fentanyl alone, although the duration of analgesia was prolonged. ${ }^{12}$ The combination of epidural sufentanil and clonidine, however, produced long-lasting and better pain relief. ${ }^{13}$ It remains unknown why the effects of concurrent epidural administration of opioids and clonidine on the analgesic intensity and duration are so varied. The most likely reason might be the absence of criteria for clear definition of analgesic efficacy and duration. If pain could be described in terms of analgesic demand which depends on the intensity of pain, the requirement of supplementary morphine via PCA could be used as a measure of pain to compare analgesic modalities. ${ }^{9}$ Therefore, the cumulative dose of supplementary PCA morphine may well be considered to reflect directly the analgesic effect of each regimen. Although sedation induced by clonidine might have interfered with the pressing behaviour of PCA button, it 
is not likely to contribute to the smaller analgesic demand of PCA morphine in the $\mathrm{M}+\mathrm{C}$ group, since no differences in the sedation score between the groups were observed beyond $3 \mathrm{hr}$ after surgery (Figure 3 ).

Epidural clonidine $2 \mu \mathrm{g} \cdot \mathrm{kg}^{-1}$ alone has provided satisfactory postoperative analgesia of short duration after orthopaedic and perineal surgery, ${ }^{2}$ whereas the need for supplementary analgesia was not affected by epidural clonidine $3 \mu \mathrm{g} \cdot \mathrm{kg}^{-1}$ in patients after thoracotomy. ${ }^{14}$ These conflicting results may be accounted for by differences in postoperative pain intensity. Also, Eisenach et al. have suggested that epidural clonidine, in doses of less than $400 \mu \mathrm{g}$, is relatively ineffective against acute postoperative pain. ${ }^{3}$ However, this small dose of 3 $\mu \mathrm{g} \cdot \mathrm{kg}^{-1}$ clonidine, which per se would fail to induce an adequate analgesia, potentiated and prolonged the thoracic epidural morphine-induced analgesia in this study. Although it is not clearly defined how the alpha ${ }_{2}$ adrenergic system is involved in analgesic mechanisms, there is some evidence favouring a synergistic interaction between alpha $a_{2}$ agonists and opioids at the spinal cord level. 6,7

Centrally mediated hypotension ${ }^{15,16}$ after epidural clonidine may be one of the major adverse effects interfering with its clinical application. The small dose of $3 \mu \mathrm{g} \cdot \mathrm{kg}^{-1}$ thoracic epidural clonidine in this study is likely to have had only a moderate hypotensive effect. Larger doses reverse the centrally mediated hypotension by a systemic vasoconstrictive effect. ${ }^{3}$ Thoracic epidural injection of clonidine is likely to have contributed to the decrease in blood pressure, since the thoracic spinal cord has been demonstrated to be the site of haemodynamic effects of intrathecal alpha $a_{2}$ agonists. ${ }^{17,18}$ The moderate hypotension responded well to $i v$ colloid infusion of about $300 \mathrm{ml}$ which was given when $i v$ ephedrine could not maintain systolic blood pressure over $90 \mathrm{mmHg}$, and it implies that adequate hydration before epidural use of clonidine is needed to prevent profound hypotension. Although bradycardia may be associated with systemic or central administration of clonidine by the same mechanisms as clonidine-induced hypotension, ${ }^{15,16}$ our data showed no change in heart rate perhaps due to the relatively small dose of clonidine. ${ }^{19,20}$

Except for moderate hypotension and drowsiness, no side effects were noted during or after thoracic epidural administration of morphine and clonidine. Although a higher degree of sedation was noted one hour after surgery in the $\mathrm{M}+\mathrm{C}$ group, comparable arterial $\mathrm{CO}_{2}$ tension was achieved in both groups after surgery. This finding shows no potentiation of epidural morphine-induced respiratory depression by addition of epidural clonidine. This is in agreement with previous studies indicating minor or no effects of alpha ${ }_{2}$ agonists on respiration. ${ }^{3,5,21}$
In summary, combined bolus administration of thoracic epidural clonidine $3 \mu \mathrm{g} \cdot \mathrm{kg}^{-1}$ and morphine 0.05 $\mathrm{mg} \cdot \mathrm{kg}^{-1}$ produces more potent and long-lasting postoperative analgesia after gastrectomy than epidural morphine alone. Hypotension was frequently observed in patients given clonidine, but it responded well to $\dot{N}$ colloid. The combined use of thoracic epidural clonidine and morphine is a promising therapeutic modality for postoperative pain management of upper abdominal surgery because of its excellent analgesia.

\section{References}

1 Mendez R, Eisenach JC, Kashtan K. Epidural clonidine analgesia after cesarean section. Anesthesiology 1990; 73: 848-52.

2 Bonnet $F$, Boico $O$, Rostaing $S$, et al. Postoperative analgesia with extradural clonidine. Br J Anaesth 1989; 63: 465-9.

3 Eisenach JC, Lysak SZ, Viscomi CM. Epidural clonidine analgesia following surgery: Phase I. Anesthesiology 1989; 71: 640-6.

4 Tamsen A, Gordh $T$. Epidural clonidine produces analgesia (Letter). Lancet 1984; 2: 231-2.

5 Motsch J, Gräber E, Ludwig K. Addition of clonidine enhances postoperative analgesia from epidural morphine: a double-blind study. Anesthesiology 1990; 73: 1067-73.

6 Omote $K$, Kitahata LM, Collins JG, Nakatani K, Nakagawa $I$. Interaction between opiate subtype and alpha-2 adrenergic agonists in suppression of noxiously evoked activity of WDR neurons in the spinal dorsal horn.

Anesthesiology 1991; 74: 737-43.

7 Ossipov MH, Suarez LJ, Spaulding TC. Antinociceptive interactions between alpha ${ }_{2}$-adrenergic and opiate agonists at the spinal level in rodents. Anesth Analg 1989; 68: 194-200.

8 Maze $M$, Tranquilli $W$. Alpha-2 adrenoceptor agonists: defining the role in clinical anesthesia. Anesthesiology 1991; 74: 581-605.

9 Sechzer PH. Patient-controlled analgesia (PCA): a retrospective. Anesthesiology 1990; 72: 735-6.

10 Nishikawa T, Dohi $S$. Clinical evaluation of clonidine added to lidocaine solution for epidural anesthesia. Anesthesiology 1990; 73: 853-9.

11 Petit J, Oksenhendler G, Colas G, Leroy A, Winckler C. Comparison of the effects of morphine, clonidine and a combination of morphine and clonidine administered epidurally for postoperative analgesia. Anesthesiology 1989; 71: A647.

12 Rostaing $S$, Bonnet F, Levron JC, Vodinh J, Pluskwa F, Saada $M$. Effect of epidural clonidine on analgesia and pharmacokinetics of epidural fentanyl in postoperative patients. Anesthesiology 1991; 75: 420-5.

13 Vercauteren $M$, Lauwers $E$, Meert $T$, de Hert $S$, Ad- 
riaensen $H$. Comparison of epidural sufentanil plus clonidine with sufentanil alone for postoperative pain relief. Anaesthesia 1990; 45: 531-4.

14 Gordh T Jr. Epidural clonidine for treatment of postoperative pain after thoracotomy. A double-blind placebocontrolled study. Acta Anaesthesiol Scand 1988; 32: 702-9.

15 Guyenet $P G, C a b o t J B$. Inhibition of sympathetic preganglionic neurons by catecholamines and clonidine: mediation by an $\alpha$-adrenergic receptor. J Neurosci 1981; 1: 908-17.

16 Häsler $G$. Central $\alpha$-adrenoreceptors involved in cardiovascular regulation. J Cardiovasc Pharmacol 1982; 4 (Suppl): S72-6.

17 Eisenach JC, Tong $C$. Site of hemodynamic effects of intrathecal $\alpha_{2}$-adrenergic agonists. Anesthesiology 1991; 74: 766-71.

18 De Kock $M$. Site of hemodynamic effects of $\alpha_{2}$-adrenergic agonists. Anesthesiology 1991; 75: 715-6.

19 Filos KS, Patroni O, Goudas LC, Bosas O, Kassaras A, Gartaganis $S$. A dose-response study of orally administered clonidine as premedication in the elderly: evaluating hemodynamic safety. Anesth Analg 1993; 77: 1185-92.

20 Nishikawa $T$, Dohi $S$. Oral clonidine blunts the heart rate response to intravenous atropine in humans. Anesthesiology 1991; 75: 217-22.

21 Bailey PL, Sperry RJ, Johnson GK, et al. Respiratory effects of clonidine alone and combined with morphine, in humans. Anesthesiology 1991; 74: 43-8. 